\title{
Identification of Cellulose Fibers Isolated from Reconstituted Tobacco*
}

\author{
by W. J. Casey and J. V. Fiore \\ The AMF Technical Center, AMF Incorporated, Stamford, Conn., U.S.A.
}

\section{INTRODUCTION}

Reconstituted tobacco, because of its advantageous economic impact on the manufacturing cost of cigars and cigarettes, has had increasing world-wide acceptance by the tobacco industry $(1,2)$. Though this economic impact continues, these materials have taken on a new dimension in that they have been found to exert significant effects on the resultant combustion products $(3,4)$. This finding has resulted in studies focused on the relationships between the structural aspects of reconstituted sheets and the biological activity of the resultant tars (3 to 8 ). Recently, the composition of these products has come under increased surveillance by governmental agencies and health organizations both in the United States and Europe. This, too, has resulted in studies on the microscopic level (9).

In the manufacture of reconstituted tobacco products, it is generally recognized that natural or synthetic fibers can be an important component of the formulation. It is these fibers that generally impart to the products the necessary tensile strength, resiliency, stretch, coherence and the like which are necessary prerequisites for proper performance in automatic machinery producing cigarettes, cigars and chewing tobacco. It is also well known, especially in the case of cellulose fibers, that the physical properties of reconstituted sheets can be greatly affected by the mechanical and/or chemical treatments the fibers may be given prior to use in a formulation (10, 11). Thus as part of a continuing effort on studies of the structural and compositional aspects of reconstituted tobacco products ( 3 to 8 ), the present study was initiated to investigate cellulose fibers, of either wood or tobacco source, in an effort to determine if the source of the fibers and the degree of pretreatment imposed upon them during the processing of these products could be identified after manufacture.

All of the cited references dealing with the structural or compositional aspects of reconstituted sheet have considered these materials microscopically on an "as-is" basis either by surface, cross-sectional or a combination of these and dye-staining techniques. The present study is a departure from this approach in that it involves isolation of the cellulosic component from the reconstituted tobacco material followed by microscopic analysis of the relatively pure cellulose. Thus, it has been

* Presented at the 28th Tobacco Chemists' Research Conference, Raleigh, North Carolina, October 28-30, 1974. demonstrated that it is possible to distinguish between cellulose fibers of wood and tobacco origin and to ascertain the approximate degree of refining the fibers may have received before incorporation into the product.

\section{EXPERIMENTAL}

Before any attempt was made to study the physical characteristics of cellulosic components isolated from reconstituted tobacco sheet, it was first necessary to establish the effects, if any, on the physical structure and appearance of cellulosic materials imposed by the cellulose chemical isolation method. Once it had been established that the isolation scheme did not alter the physical structure and appearance of cellulose, we determined the effects which the processing conditions used in preparing reconstituted tobacco sheets have on the cellulose components. For these studies, a baseweb system was used. This consisted of a chemical formulation used in reconstituted sheet production but whithout the requisite amount of tobacco. This made it relatively easy to isolate and study the cellulosic components. It was found that Microflake ${ }^{(\mathrm{TM})}$ reconstituted tobacco processing in no way affected the cellulosic material. The approach was to then apply these methods to known and unknown reconstituted tobacco sheets.

Throughout these experiments we used cellulose in the form of an unbleached sulfite pulp as the wood source and tobacco stem pulps as the tobacco source. Both materials were studied with and without further mechanical refining. The degree of refining or freeness with respect to the paper pulp has been reported as Canadian Standard Freeness (CSF) while that of stem pulp is reported as Schopper-Riegler Freeness (SRF). The reason for this is that the inversion point on the CSF scale occurs at a much larger particle size than on the SRF scale and is therefore not as useful an indication of when stem pulp has reached the state of refining needed for reconstituted tobacco sheet manufactured by the slurry process (II). It is known that the effective upper limit of freeness on the CSF scale ( -850 CSF) corresponds approximately to the inversion point on the SRF scale ( $\pm 50 \mathrm{SRF})$. Since many of our freeness values are in the negative or inverted freeness range (i.e., in the portion of the refining curve where freeness values are rising as refining proceeds) and these values are uncommon in the pulp and paper industry, a brief discussion of freeness determination is included. 
The freeness test is wholly empirical and gives an arbitrary measure of the rate at which a suspension of pulp (usually $3 \mathrm{~g} /$ liter of water) may be drained or dewatered. The test is performed by measuring the volume of water overflowed through a standard screen into a receiver which has a controlled orifice outlet. When the fibers are large, they will tend to form a loosely packed mat which allows water to easily flow through the screen. As the fibers become more refined, they tend to interlock with one another and form a tighter mat which hinders the flow of water through the screen. Therefore, as the volume collected decreases, this indicates the pulp is becoming more refined. If, however, the pulp becomes so fine that it flows through the screen with the water, then this volume of fiber plus water is collected and measured. These latter values are referred to as negative or inverted. In this case, as the volume collected increases, it indicates that the fibers are becoming more highly refined.
In the region of zero freeness, one is not always definite which sign is to be given a particular reading. Instead of taking many samples and carefully defining the zero, one sometimes calls freeness values in this region plus or minus rather than specifying the exact sign. Some of the wood pulp samples mentioned in this paper will be referred to in this manner.

\section{CELLULOSE ISOLATION}

The procedure used for the extraction of cellulose from the reconstituted tobacco sheet is shown diagrammatically in Figure 1 . It is essentially the procedure as outlined by Christy and Samfield which isolates $\alpha$-cellulose via a delignification process (12). This isolation method was found to cause only a minimum of degradation to the cellulose fibers. The major modification introduced into the scheme concerned the initial treatment of the

Figure 1. Procedure for cellulose isolation.

1.

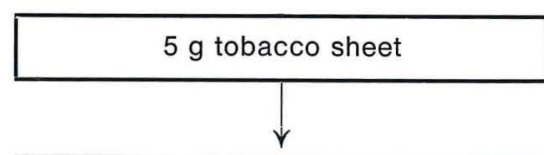

2.

3
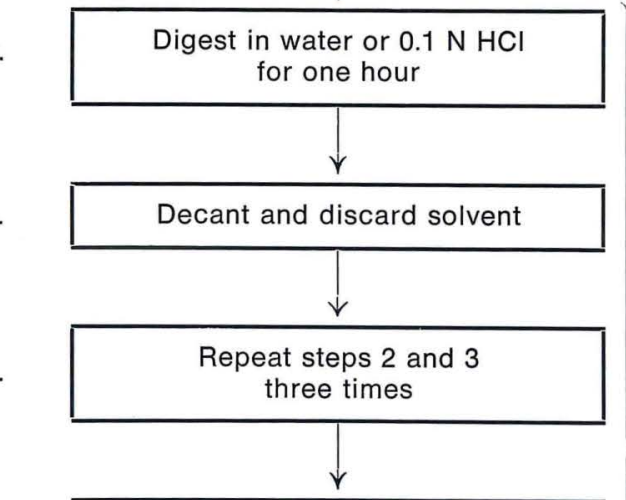

5.

Use stirring rod and slight stirring action to disintegrate sheet

6.

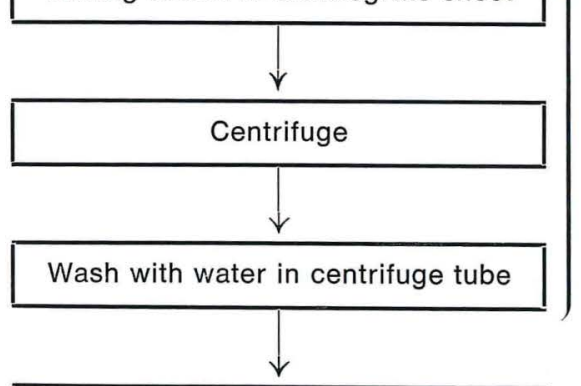

8.

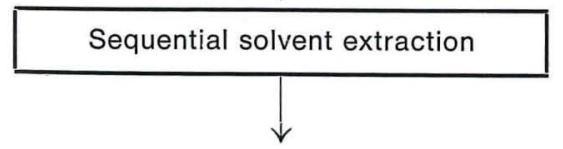

a. Water - 12 hours

b. Ethyl alcohol $(95 \%)-6$ hours

c. Acetone -3 hours

d. Benzene -3 hours

e. Acetone -1 hour

9.

Press to remove excess acetone
16.

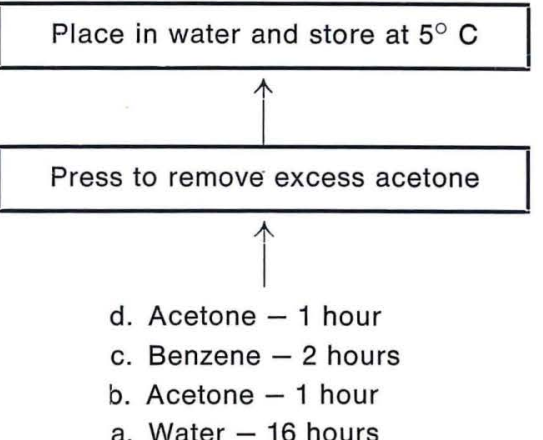

14.

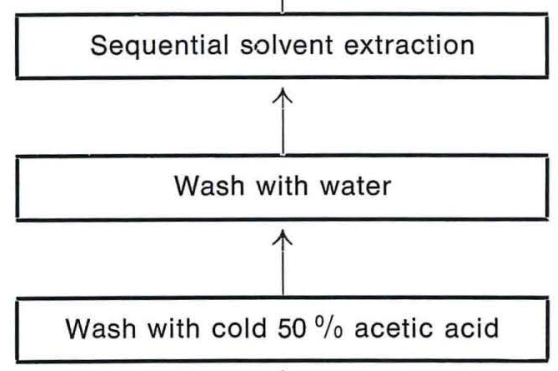

11.

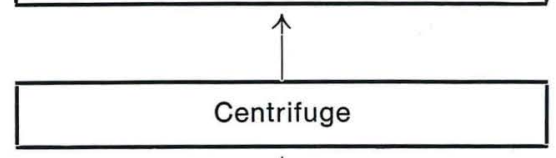

10.

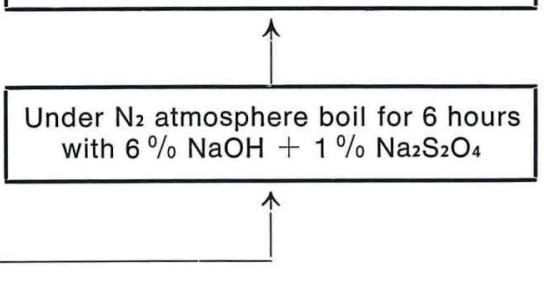


tobacco sheet in that no mechanical action was applied to aid the disintegration as recommended by Christy and Samfield. Samples of reconstituted tobacco, which were cut approximately $I^{\prime \prime} \times I^{\prime \prime}$, were disintegrated only by exposure to water or dilute hydrochloric acid, depending upon the wet-strength inherent in the particular material. The resultant slurry was centrifuged, washed several times in the centrifuge tube and transferred to Soxhlet extraction apparatus for the sequential solvent extractions; the delignification step was followed by the final series of extractions. Sodium dithionite was added during the delignification (step to in Figure 1) as an oxygen scavenger to decrease oxidation of the cellulose. The entire delignification process was carried out under a blanket of nitrogen.

\section{PHOTOMICROSCOPY}

Dilute aqueous suspensions of the isolated cellulose were prepared for each sample. A small amount of this material was examined in a light microscope using polarized light and a representative area was then photographed.

When a sample is viewed with polarized light, only birefringent material is seen and this is invariably associated with crystalline structure or molecular orientation. Such orientation is commonly found in cellulose fibers. In the polarized light photographs which follow, the background appears black and all cellulose matter appears white.

\section{CELLULOSE SAMPLES}

In this study, two types of cellulosic materials were used as reference standards. Both were prepared in our laboratory. The first was a sample of unbleached sulfite wood pulp which was taken through the beating process in a paper pulp disc-type refiner. During refining, materials were removed at various stages; the range from +450 to -640 CSF was sampled. Since this pulp was originally isolated from wood by a chemical treatment, the samples were microscopically analyzed without first subjecting the material to the cellulose isolation scheme presented in Figure 1. However identical samples were also treated by the complete chemical isolation scheme and again microscopically analyzed. This established that the isolation scheme does not in any way alter the physical appearance of cellulose. Initially these samples were used as standard materials for the identification of differences between refined and unrefined wood pulp and later for comparison with unknown cellulose samples.

In order to ascertain the extent of particle size change that occurs during refining, an image analysis was conducted on samples representing various stages of mechanically refined pulp (13). This data is graphically

Figure 2. Summary of image analysis data.

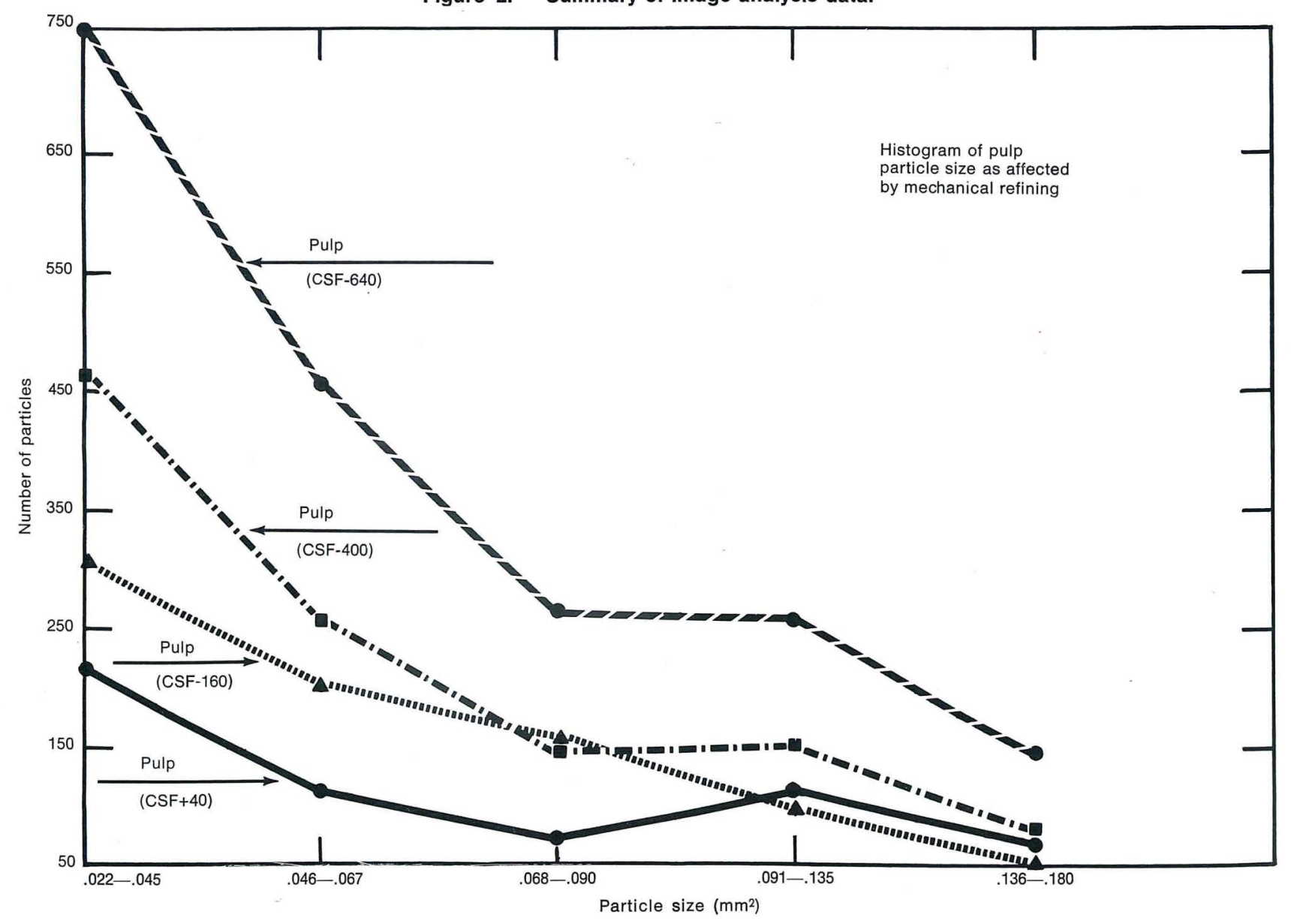


presented in Figure 2 where particle size is plotted versus population density in the field of analysis. It is obvious that as the degree of refining increases, the number of smaller particles increases. This is the expected result. The interesting feature, however, is that the largest differences in population density are in a size region which can be observed microscopically.

The second source of cellulose was tobacco stems and for this purpose, a mixture of Bright and Burley tobacco was used. The stems were taken through the beating process in a paper pulp disc-type refiner and again samples were removed at various stages; sampling was over the range from +430 to -950 SRF. Since it had already been established that the chemical isolation scheme does not alter the physical appearance of cellulose and since tobacco stems contain materials other than cellulose, all these samples were carried through the cellulose isolation scheme before microscopic examination.

\section{RESULTS AND DISCUSSION}

In Figure 3 are presented photomicrographs of tobacco stem (Pictures A, B) and wood pulp (Pictures C, D) at an initial and a subsequent stage of refining. The magnification is $70 \times$. In essence, this Figure is a summary of the four cellulose types studied.

At this magnification, the distinctions between wood pulp $\alpha$-cellulose and tobacco stem $\alpha$-cellulose are clearcut and easily made. The width of the cellulose pieces from tobacco stem pulp is five or six times the average width of the typical wood cellulose pieces in the unrefined samples. Also, the tobacco stem bundles appear striated; that is, they have alternate areas of birefringence and non-birefringence. On the other hand, in the case of wood pulp, the fibers are bound very closely together and the birefringence seems to be uniform or continuous; striations are not obvious. For the case of refined cellulose, it is still possible to distinguish the tobacco derived material from the wood based material. Some of the tobacco cellulose pieces are again greater in width than the wood cellulose pieces, and there are still striations evident in the tobacco bundles. Additionally, very thin cellulose pieces now present in these photographs of refined pulp (Pictures B and D in Figure 3) are significant. They are called fibrils and result from the well known process of fibrillation which occurs when mechanical beating is applied to cellulose fibers. For tobacco stems, many of these fibrils are circular, while in the case of wood pulp the fibrils are relatively linear. These features are again shown in Figure 4 ; the photographs shown were taken at three times the magnification as those contained in Figure 3. The striations and helical structure present in tobacco stem cellulose (Picture A in Figure 4) are more easily discernible compared to the uniform, ribbon-like structure of wood cellulose (Picture B in Figure 4 ). Picture C (Figure 4) of fibrils from highly refined wood pulp emphasizes their thread-like nature versus the circular nature for some of the stem fibrils.
During these studies, it was considered that scanning electron micrographs (SEM) might yield more structural information of the cellulose than light microscopy. Photographs taken with a scanning electron microscope are presented in Figure 5. It can be seen that the cellulose extraction process (Picture B in Figure 5) does not alter the physical appearance of the wood cellulose (Picture A in Figure 5) except perhaps in opacity. The appearance of fibrils in Picture B (Figure 5) is due to the refining process. On the other hand Picture $C$ (Figure 5) brings out the unique structure of the tobacco cellulose: i.e., the striations appear as a definite structure of ridges and valleys with the helical formations running in a perpendicular direction. Even though these are very striking photographs, they do not add significantly to the information obtained with a light microscope and polarized light. For this reason, no further work was done with SEM.

A comparison of tobacco stem cellulose at various stages of refining is shown in Figure 6. Picture A (SRF + 430 ) is the least refined sample, while Picture D (SRF -960) is the most refined. In general, it can be seen that there is a dramatic decrease in the average size of the cellulose pieces during refining. These smaller bundles, which are made up of two or three strands of cellulose, have a well-defined fine structure, which is very characteristic of tobacco-derived stem cellulose. Clearly, they appear to be made up from helices or spiral elements (14). The presence of these spiral elements in the $\alpha$-cellulose isolated from a reconstituted tobacco sheet may be taken as evidence for the presence of stem in that product. Also, from these photographs, it can be seen that a large percentage of the fibrils obtained are circular or " $U$ " shaped. These fibrils must be derived from the shattering of the helical element of which the cellulose is composed.

The study of wood cellulose, after various degrees of refining, is presented in Figure 7 . The major effect of mechanical treatment is, again, a decrease in the size of the fiber and the formation of fibrils. The difference between wood pulp at CSF $+_{40}$ and CSF -640 is obvious and clear-cut. On the other hand, the differences between the samples represented by Pictures B and $C$ (Figure 7) are not as clear-cut at this magnification, however, both of these stages of refinement are easily distinguished from samples of CSF +40 and -640 .

Figures 8 and 9 show the results obtained with standard and chemically isolated wood pulps of CSF \pm 50 and -650 respectively. It can be seen that neither the cellulose isolation scheme (Picture B) nor its isolation from either baseweb (Picture C) or reconstituted tobacco (Picture D) change the structural identity of the original cellulose (Picture A). Both the source of the cellulose, i.e., from wood, and its degree of refining are relatively easy to define. Since Picture D (Figures 8 and 9) is representative of wood cellulose isolated from a reconstituted tobacco sheet, one can conclude that it is possible to identify this material even in the presence of tobacco. 
We applied this cellulose identification procedure to six commercially available reconstituted tobacco sheets which had been used either as wrappers, binders or fillers in the commercial cigars selected. Cellulosic material isolated from four of these products is shown in the photomicrographs in Figure 10. All of these products employ wood pulp in their formulations. The wood pulp in Pictures $A$ and $B$ appears to be in the region $\pm 50 \mathrm{CSF}$ : that in Picture $C$ approximately -200 CSF and the cellulose shown in Picture D is judged to be -600 CSF.

Cellulosic material isolated from the remaining two commercial products is shown in Figure 11 (Pictures A and B). As can be seen, these materials do not contain wood pulp. It is also striking that there are relatively few fibrils present. For comparison purposes, in the same figure are presented photographs of $\alpha$-cellulose isolated from Pennsylvania stem dust and leaf dust (Pictures $C$ and D) respectively. It is apparent if one makes a composite of Pictures $C$ and D (Figure II) and then examines Pictures A and B (Figure 1I) that the cellulose in these commercial samples does not come from added or extraneous cellulosic material but rather from the tobacco dust used in the manufacture of these products. Note that unlike the cellulose isolated from tobacco stems, tobacco dust does not show the presence of helical or "U" shaped fibrils.

\section{CONCLUSION}

Cellulose can be isolated from tobacco or tobacco products with essentially no change in the physical character of that cellulose. This cellulose can be rather easily identified as being either wood-based or derived from tobacco, and the degree of refining given the cellulose before it is incorporated into the reconstituted sheet can be estimated within a relatively narrow freeness range.

\section{SUMMARY}

It is well known that the physical characteristics of natural fibers, particularly those of vegetable or cellulosic origin, can be controlled within well-defined limits by the chemical pulping methods and by the degree of refining to which they are subjected. It has been found that when such materials are subjected to a mild chemical treatment for the isolation of the cellulose, the isolated cellulose fiber, under microscopic analysis, has retained its physical identity despite the chemical exposures. This technique has been successfully applied to reconstituted tobacco as a means of identifying the source of the cellulose used in its manufacture. Not only can the source of the cellulose be determined as being from tobacco or wood, but the degree of refining to which these constituents were subjected prior to conversion into the reconstituted product can be easily ascertained. Photomicrographic proof for the validity of these statements is presented.

\section{ZUSAMMENFASSUNG}

Die physikalischen Eigenschaften von Naturfasern, vor allem von Pflanzen- oder Cellulosefasern, können bekanntlich innerhalb genau bestimmter Grenzen gesteuert werden durch die chemischen Aufbereitungsverfahren und durch den Grad der Veredelung, dem man sie unterwirft. Bei milder chemischer Behandlung dieser Materialien zur Isolierung der Cellulose hatte sich durch mikroskopische Untersuchung gezeigt, daß die isolierte Cellulosefaser ihre physikalische Identität trotz der chemischen Prozesse, denen sie ausgesetzt war, behielt. Diese Technik wurde erfolgreich bei Folientabak zur Bestimmung der Herkunft der bei dessen Herstellung benutzten Cellulose angewendet. Es kann so nicht nur der Ursprung der Cellulose aus Tabak oder Holz bestimmt werden, sondern auch der Veredelungsgrad, dem diese Bestandteile unterzogen wurden, bevor sie in das Folienprodukt umgewandelt wurden, kann leicht ermittelt werden. Zum Beweis der Gültigkeit dieser Feststellungen werden Mikrophotographien gezeigt.

\section{RESUME}

Il est un fait connu qu'on peut contrôler, dans des limites bien établies, les propriétés physiques de fibres naturelles, en particulier de fibres provenant de source végétale ou cellulosique, par les méthodes de "pulping» chimiques ainsi que par le degré de raffinage auquel elles sont soumises. On a trouvé qu'en soumettant ces substrats à un traitement chimique modéré afin d'isoler la cellulose, la fibre cellulosique isolée, sous analyse microscopique, conserve son identité physique, et ce malgré le traitement chimique. On a appliqué cette méthode avec succès au tabac reconstitué en feuille afin de déterminer la provenance de la cellulose employée à sa fabrication. On peut ainsi non seulement déterminer l'origine de la cellulose, notamment le tabac ou le bois, mais aussi donner avec certitude et facilement le degré de raffinage auquel ces constituants ont été soumis avant d'être incorporés dans le produit reconstitué. Des photos micrographiques prouvent la validité de ces déductions.

\section{REFERENCES}

I. Moshy, R. J.: The technology and economics of reconstituted tobacco leaf (Part I); Tobacco 160 (1965), No. 1, p. 15.

2. Moshy, R. J.: The technology and economics of reconstituted tobacco leaf (Part II): Tobacco 160 (1965), No. 2, p. 12.

3. Halter, H. M., T. I. Ito, and J. M. Slanski: Tobacco density effects on combustion and smoke composition; presented at the $5^{\text {th }}$ International Tobacco Scientific Congress, Hamburg, Germany, September 14-19, 1970 . 
4. Moshy, R. J., and H. M. Halter: Reconstituted tobacco leaf technology - A tool for tobacco smoke modification; National Cancer Institute Monograph No. 28, Toward a less harmful cigarette (June, 1968).

5. Moshy, R. J.: Smoke and physical structure - A new dimension in tobacco technology; Tobacco 162 (1966), No. I, p. 22.

6. Moshy, R. J., and R. E. Lang: Smoke and physical structure - cigars; presented at the $4^{\text {th }}$ International Tobacco Scientific Congress, Athens, Greece, September 19-26, 1966.

7. Halter, H. M., and T. I. Ito: Reconstituted tobacco - Smoking and health possibilities; Journal of the National Cancer Institute 48 (1972) 1869.

8. Halter, H. M., T. I. Ito, J. V. Fiore, T. K. Kelly, and J. M. Slanski: Comparison of low density tobacco products - foamed, puffed, freeze-dried; presented at the Coresta/TCRC Joint Conference, Williamsburg, Virginia, October 22-28, 1972.

9. Jodl, R., and F. Krüll: Mikroskopische Untersuchungen an Tabakfolien; Beitr. Tabakforsch. 7 (1974) 263.
Io. Osborne, R. J.: Tobacco sheet manufacture; U.S. Patent No. 3,125,098 (1964).

11. Light, H. J., and R. J. Osborne: Reconstituted sheet manufacture; U.S. Patent No. 3,464,422 (I969).

12. Christy, M. G., and M. Samfield: The average degree of polymerization (D.P.) of cellulose in various tobacco types, Part 1 : Experimental; Tobacco Science 4 (1960) 33.

13. Image analysis data furnished through the courtesy of Image Analysing Computers, Inc. (Imanco), of Monsey, New York.

14. Richards, G. N.: A fiber analysis of tobacco stem and stalk; Tobacco Science 8 (I964) 27.

\section{Acknowledgements}

The authors wish to express their appreciation to Mr. W. M. Suhy for assistance in preparation of samples and Mr. J. M. Slanski for guidance in the collection of photomicrographs.

The authors' address:

The AMF Technical Center, AMF Incorporated, 689 Hope Str., Stamford, Connecticut, 06907, U.S.A.

Figure 3. Effects of refining on wood and tobacco cellulose $(70 \times)$.

A: Tobacco stem pulp (SRF +430$)$

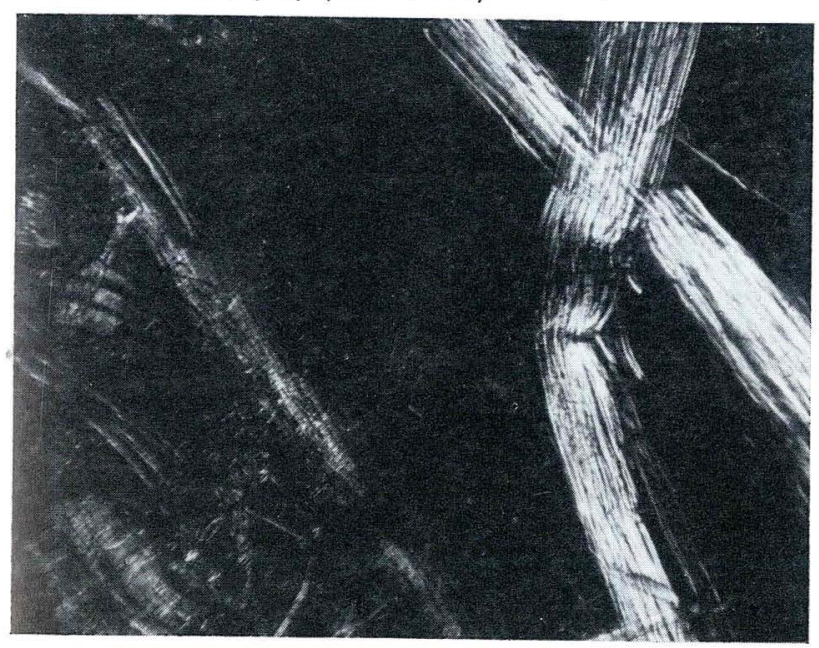

C: Wood pulp (CSF +450$)$

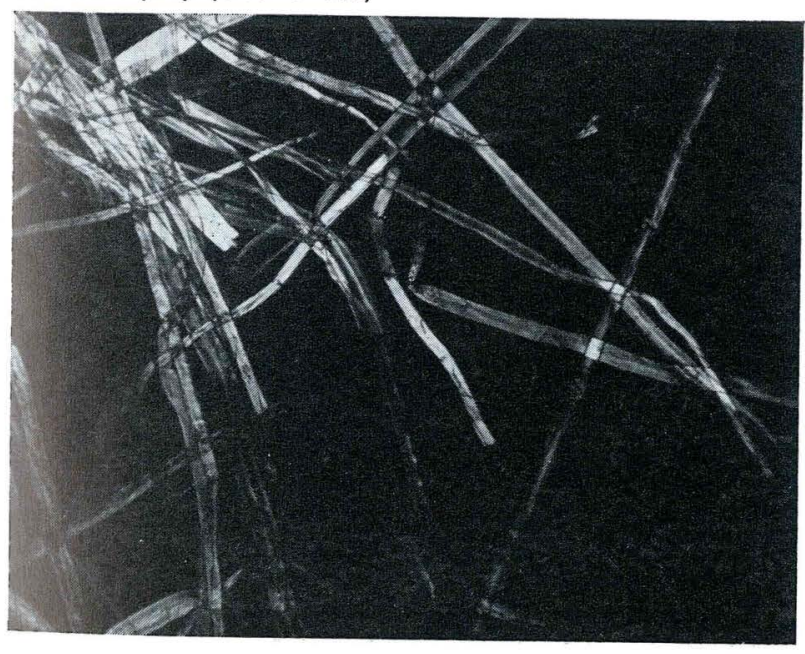

B: Tobacco stem pulp (SRF - 440)

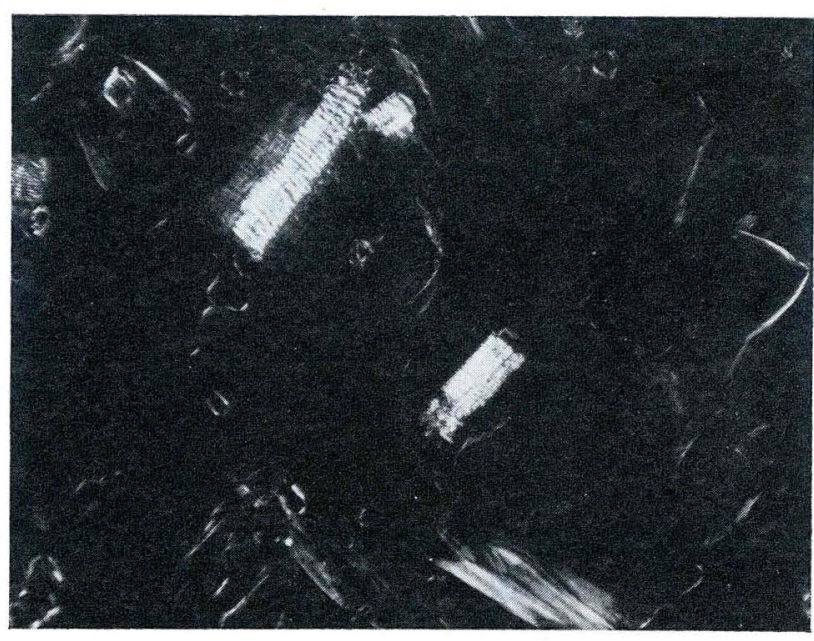

D: Wood pulp (CSF - 400)

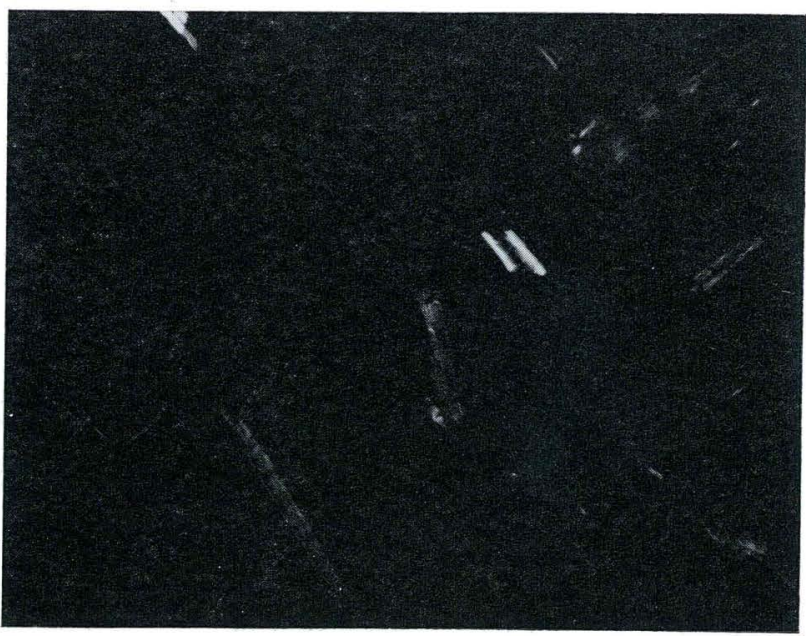


Figure 4. Tobacco and wood cellulose $(250 \times)$.

A: Tobacco stem pulp (SRF - 440)

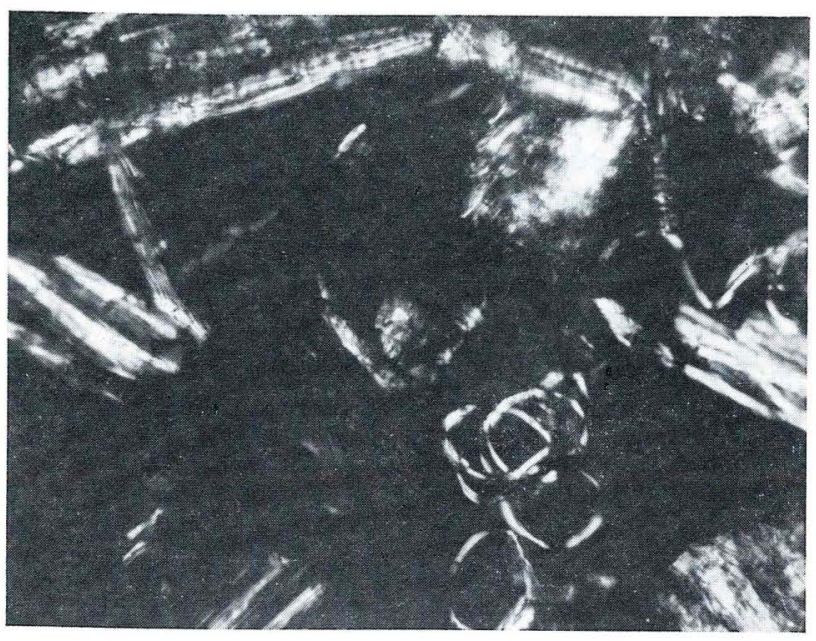

B: Isolated wood pulp (CSF +40$)$

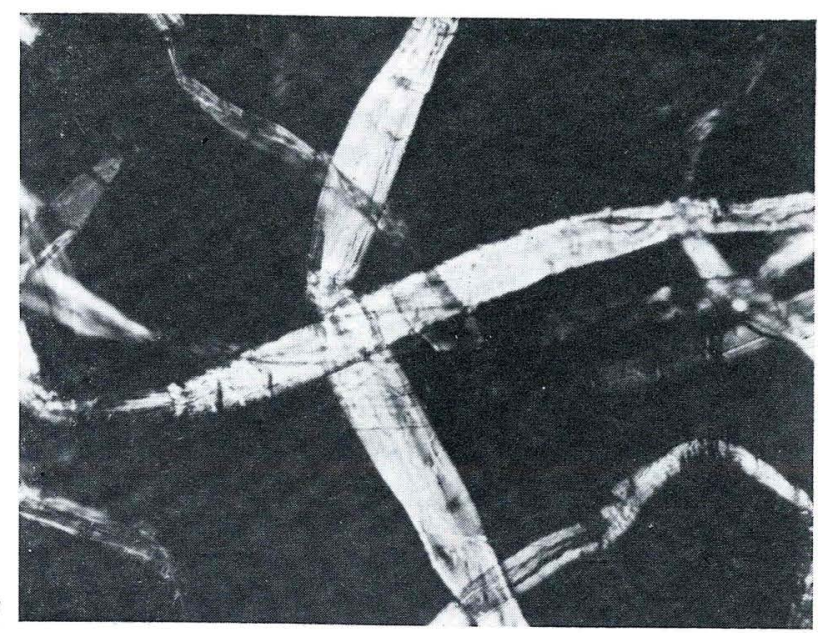

C: Isolated wood pulp (CSF - 650)

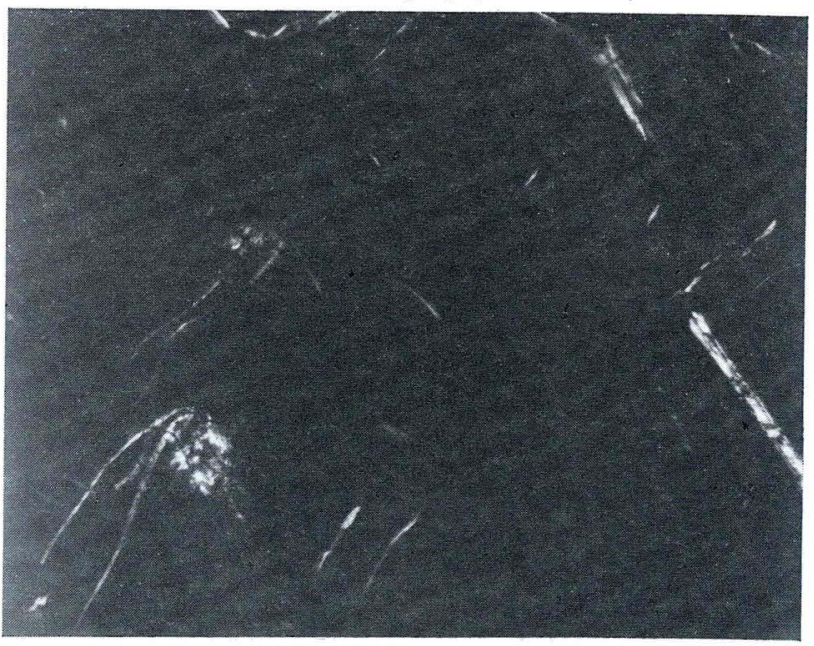

Figure 5. Scanning electron micrographs of wood and tobacco cellulose $(450 \times)$.

A: Wood pulp $(\mathrm{CSF}+450)$

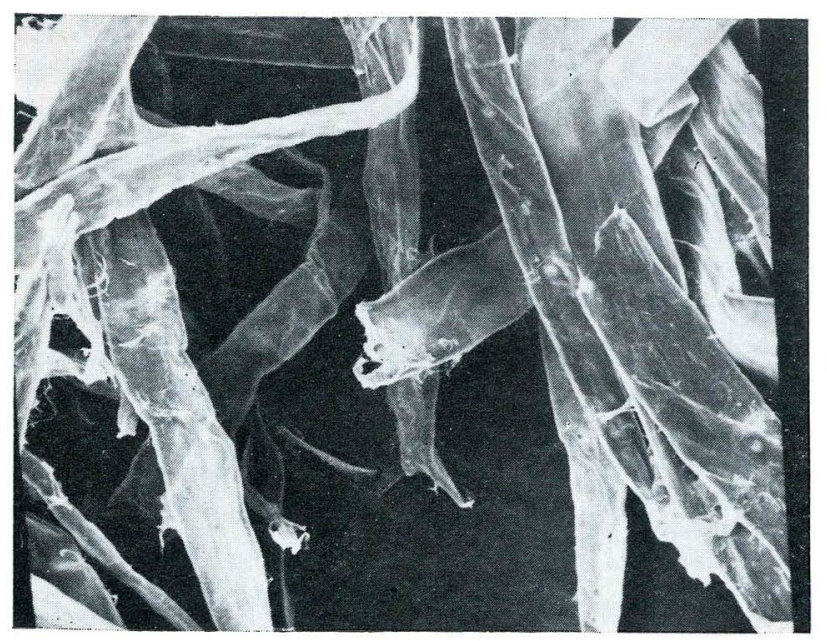

B: Isolated wood pulp (CSF +40 )

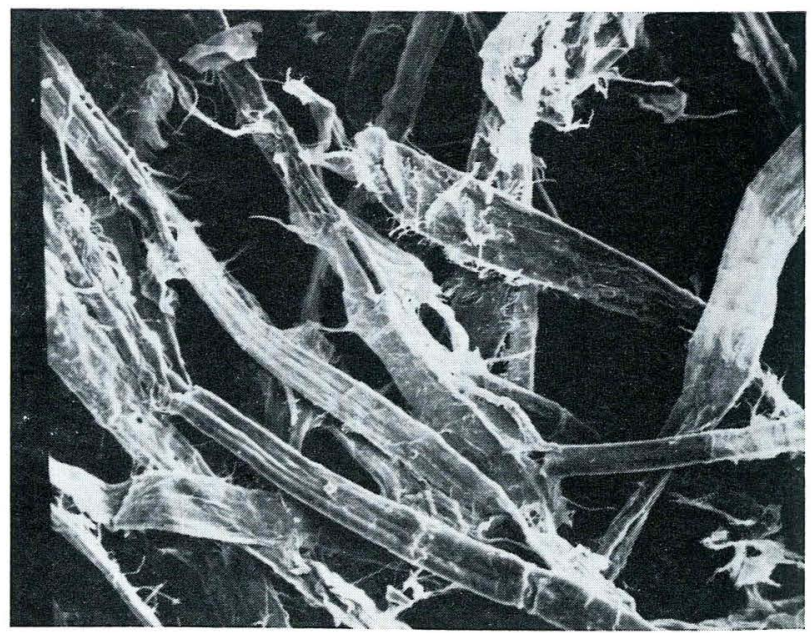


C: Isolated tobacco stem pulp (SRF +430$)$

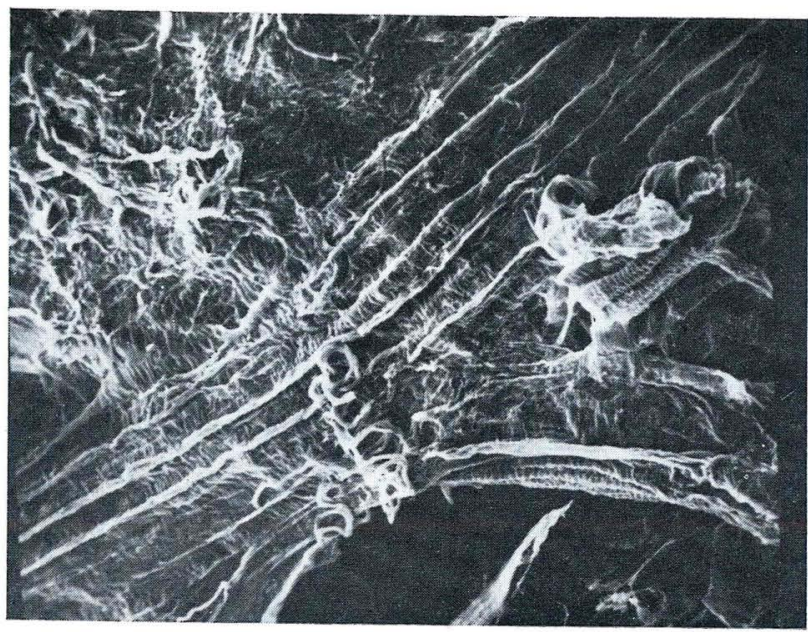

Figure 6. Isolated tobacco stem cellulose $(70 \times)$.

A: Tobacco stem puip $(\mathrm{SRF}+430)$

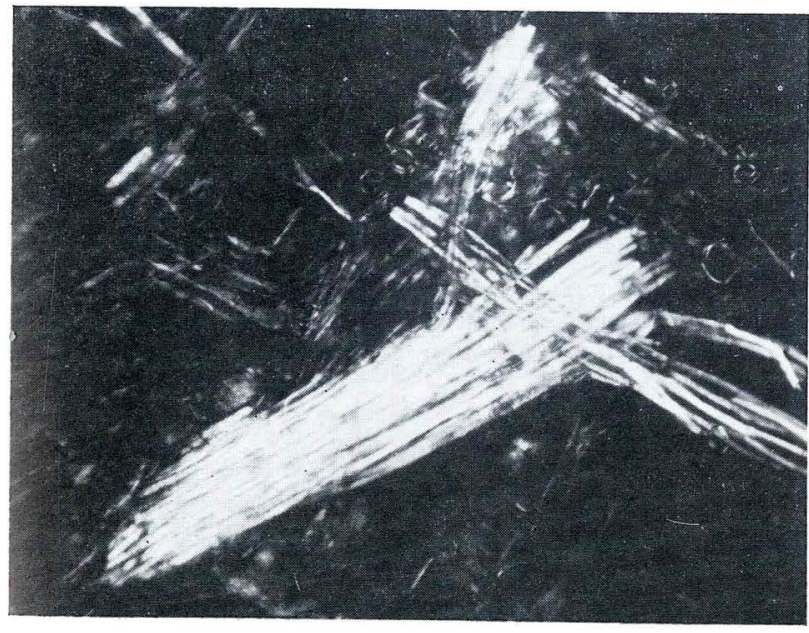

C: Tobacco stem pulp (SRF - 610)

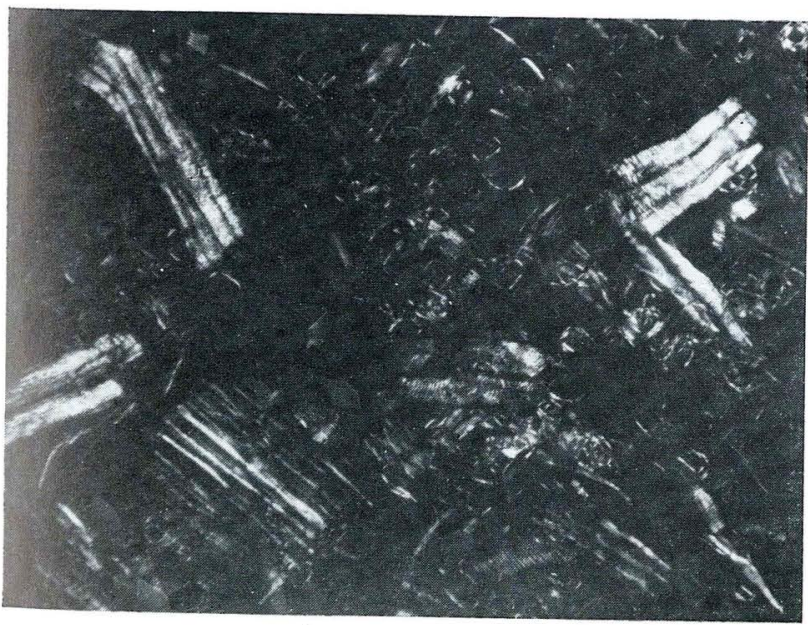

B: Tobacco stem pulp (SRF +400$)$

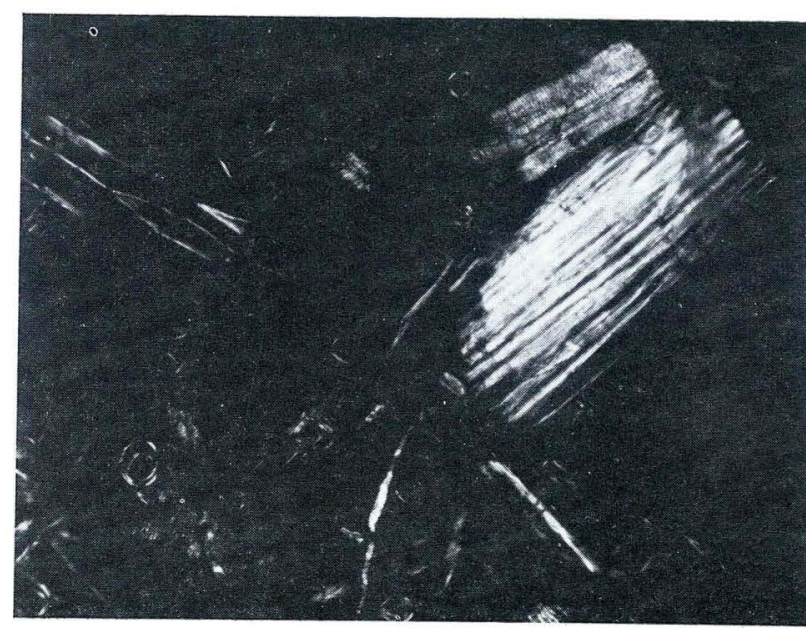

D: Tobacco stem pulp (SRF — 960)

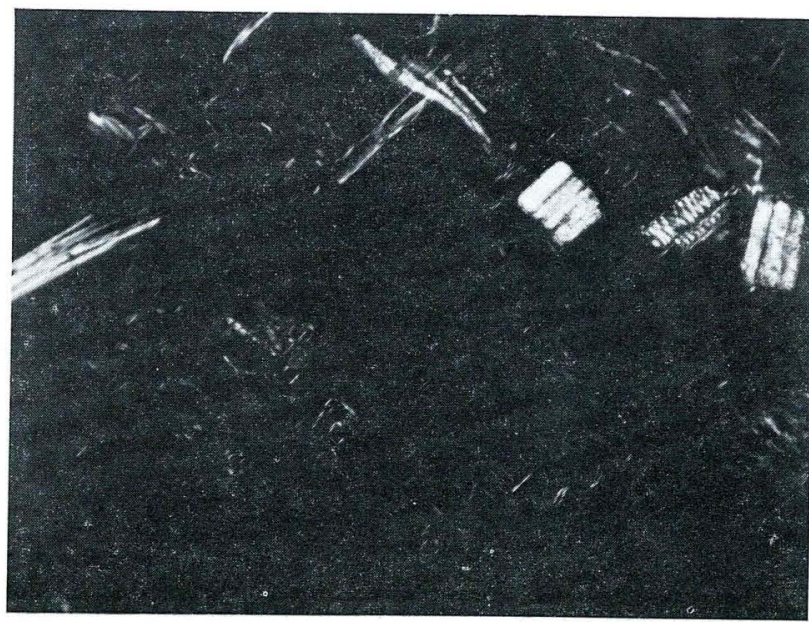



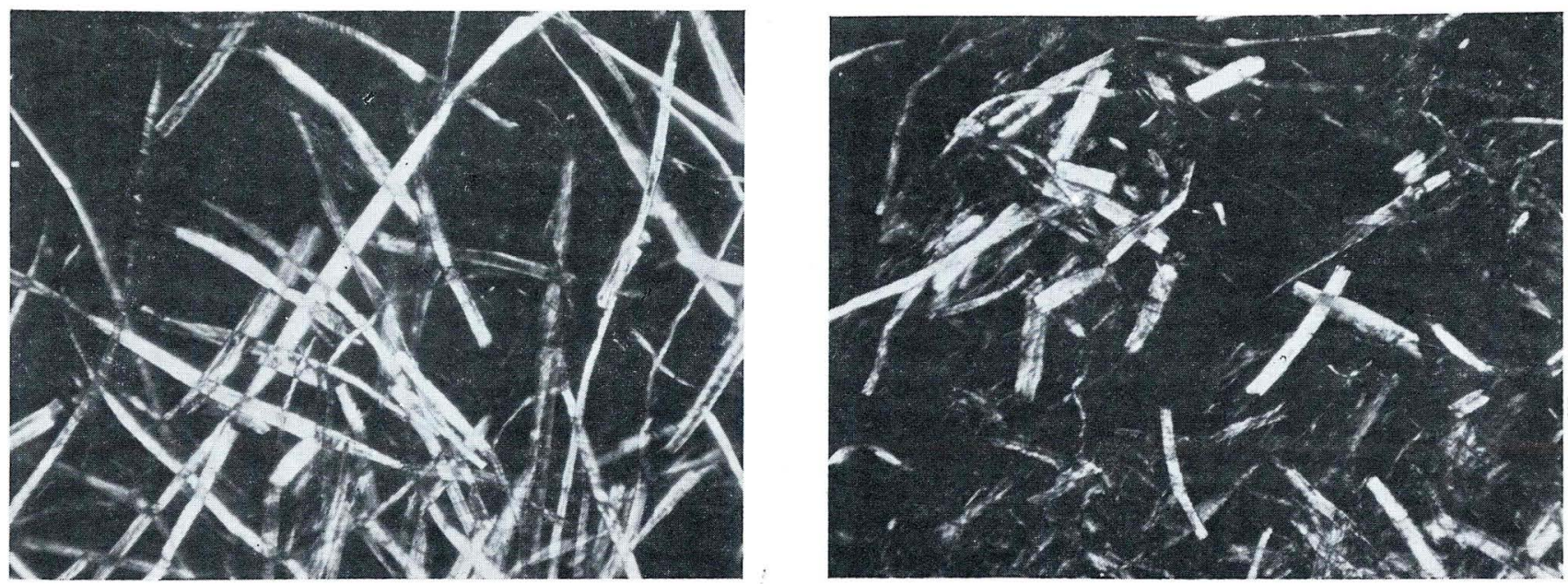

C: Wood pulp (CSF - 400)

D: Wood pulp (CSF - 640)
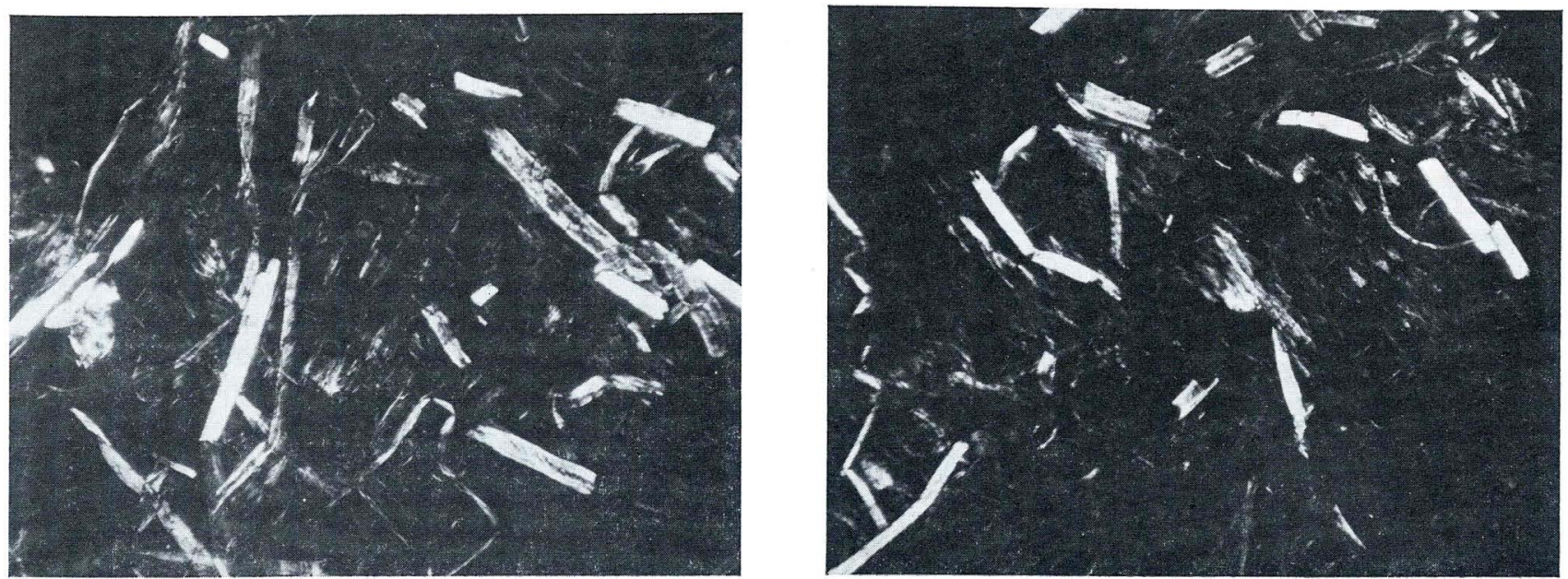

Figure 8. Isolated wood pulp / CSF $\pm 50(70 \times)$.

A: Wood pulp (CSF \pm 50$)$

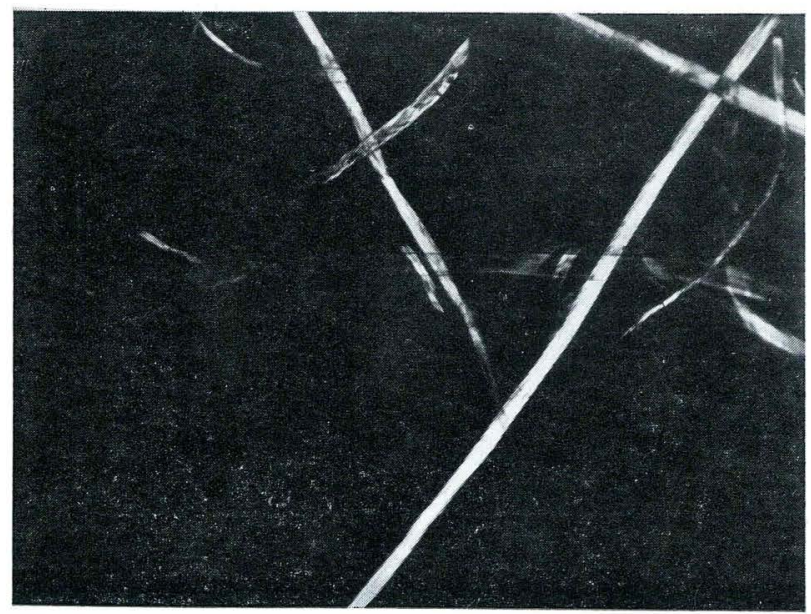

B: Isolated wood pulp (CSF \pm 50$)$

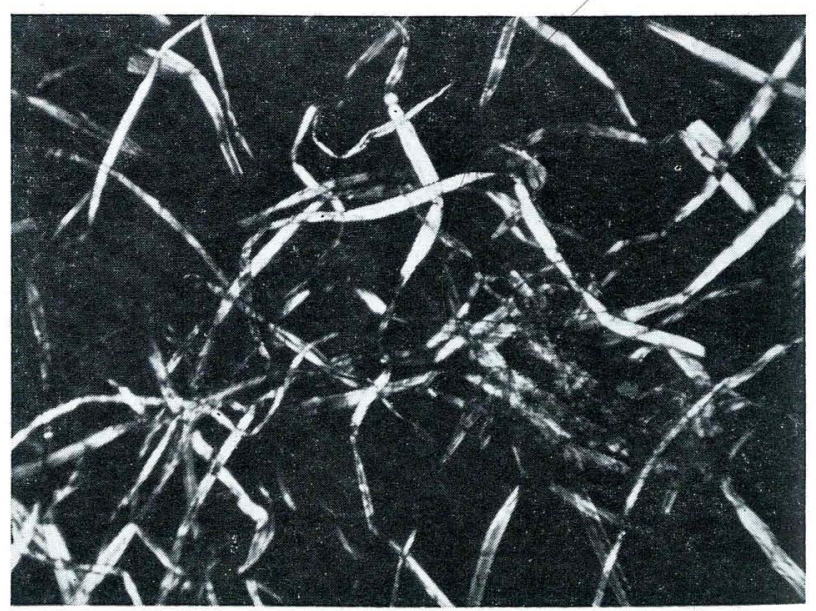


C: Wood pulp isolated from baseweb (CSF \pm 50$)$

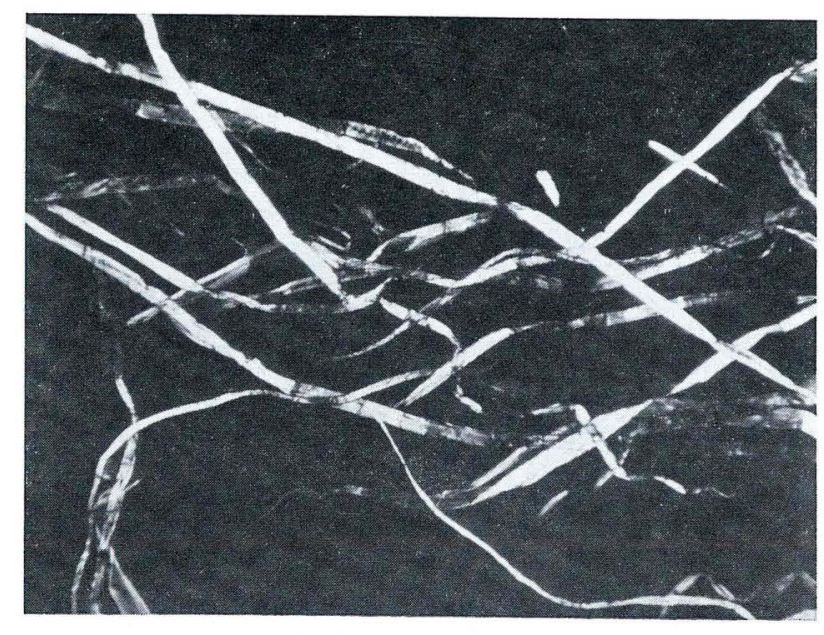

D: Wood pulp isolated from reconstituted sheet (CSF \pm 50$)$

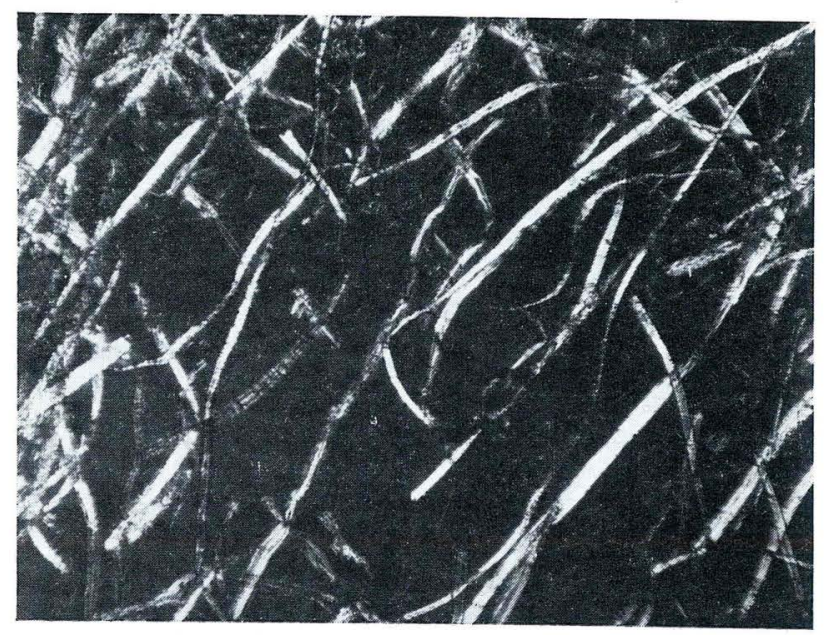

Figure 9. isolated wood puip / CSF - $650(70 \times)$.

A: Wood pulp (CSF - 650)

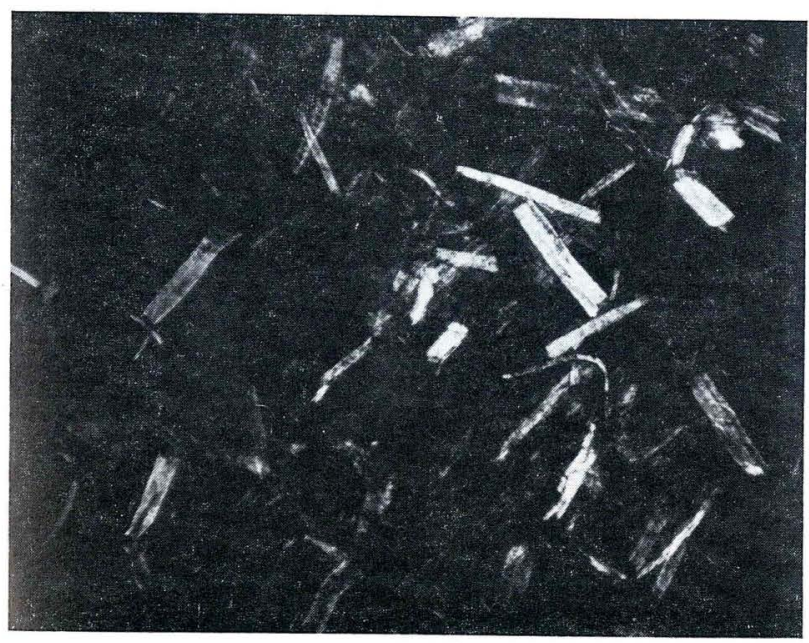

C: Wood pulp isolated from baseweb (CSF - 650)

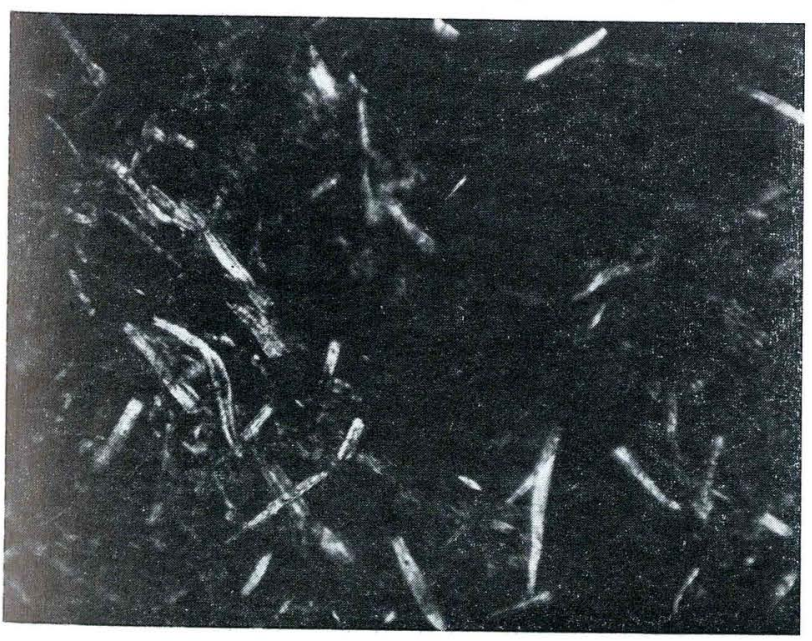

B: Isolated wood pulp (CSF - 650)

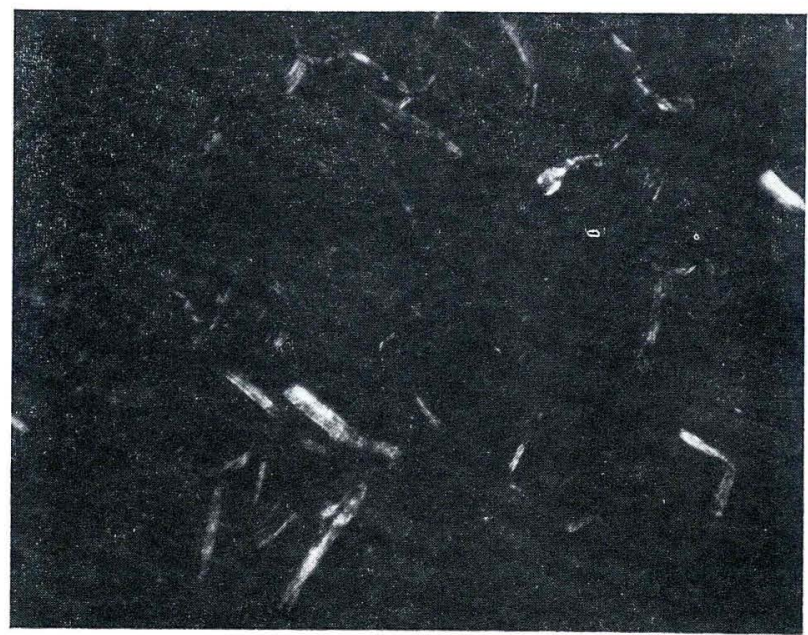

D: Wood pulp isolated from reconstituted sheet (CSF - 650)

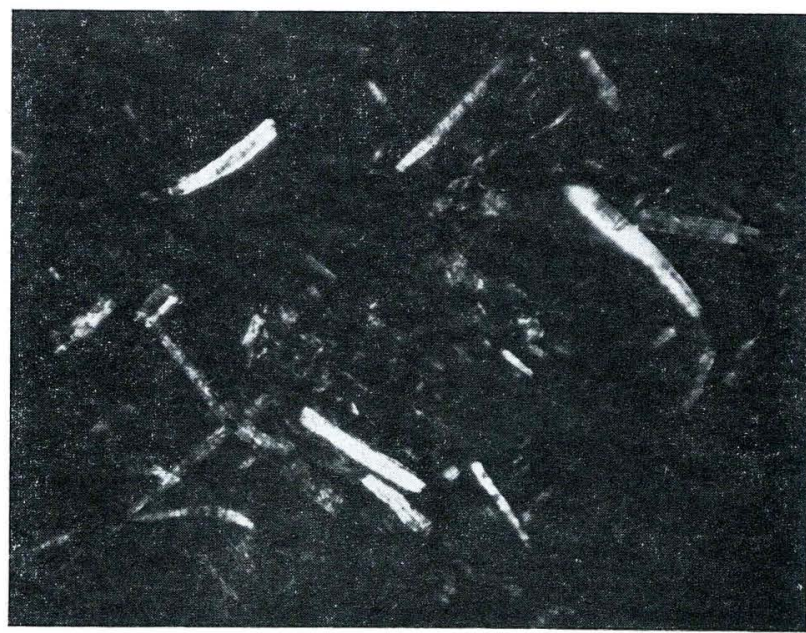


Figure 10. Cellulose isolated from commercial reconstituted products $(70 \times)$.

A: Cigar sheet 1

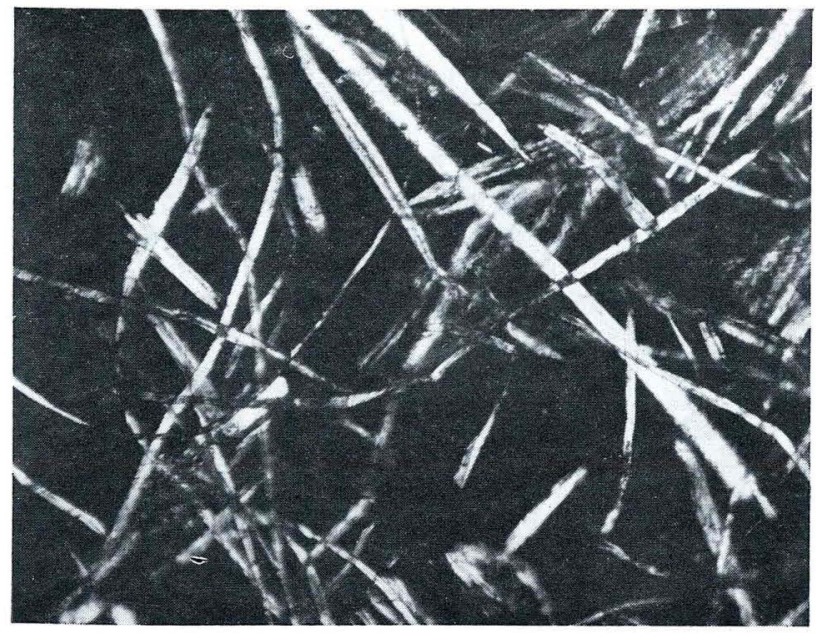

C: Cigar sheet 3

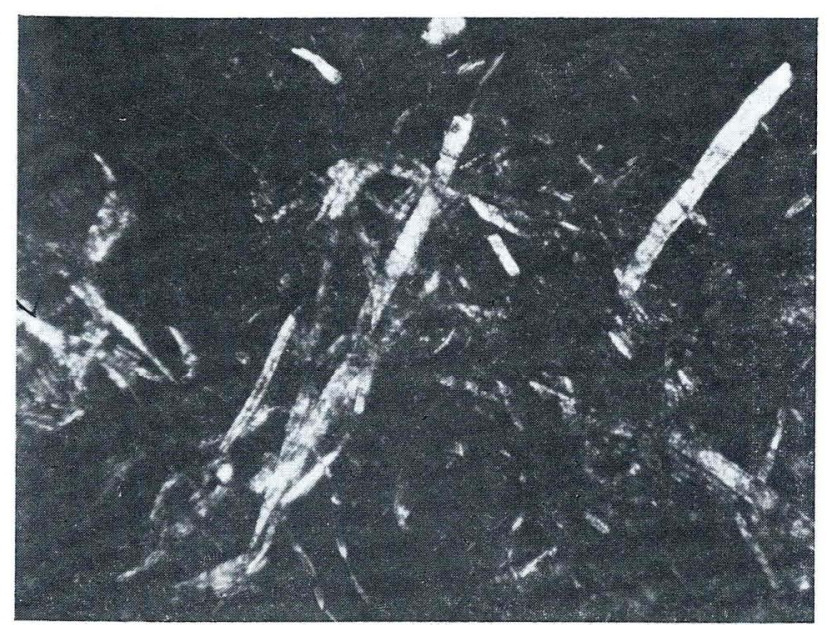

B: Cigar sheet 2

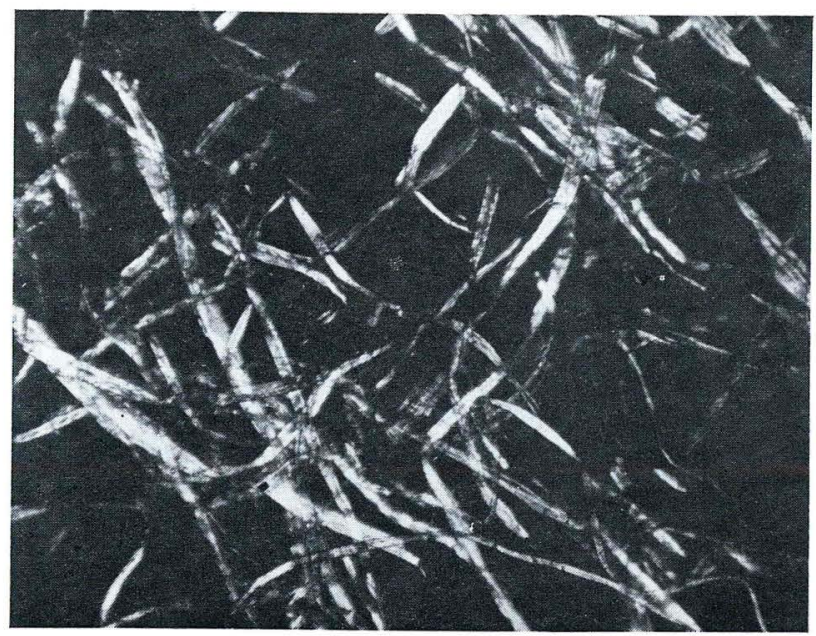

D: Cigar sheet 4

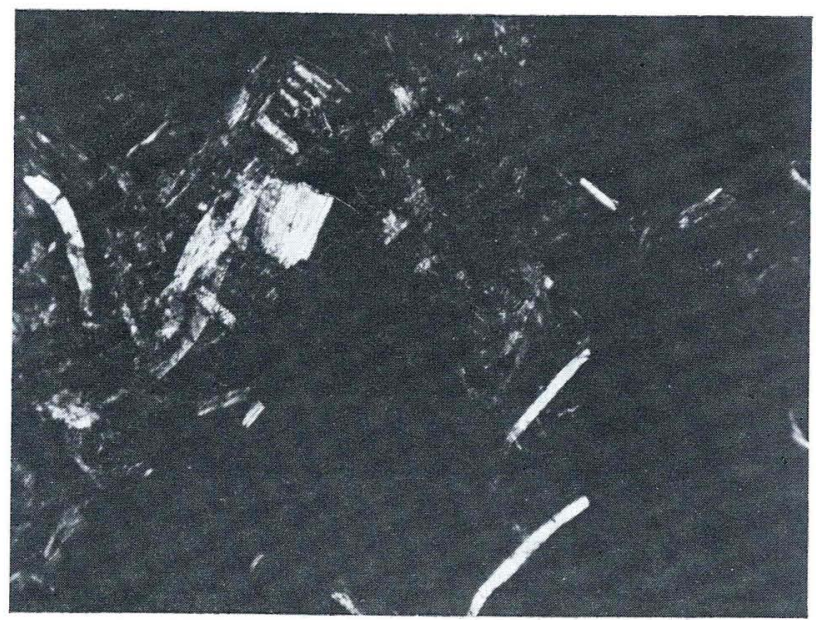

Figure 11. Cellulose isolated from commercial reconstituted products and tobacco dust $(70 \times)$.

A: Cigar sheet 5

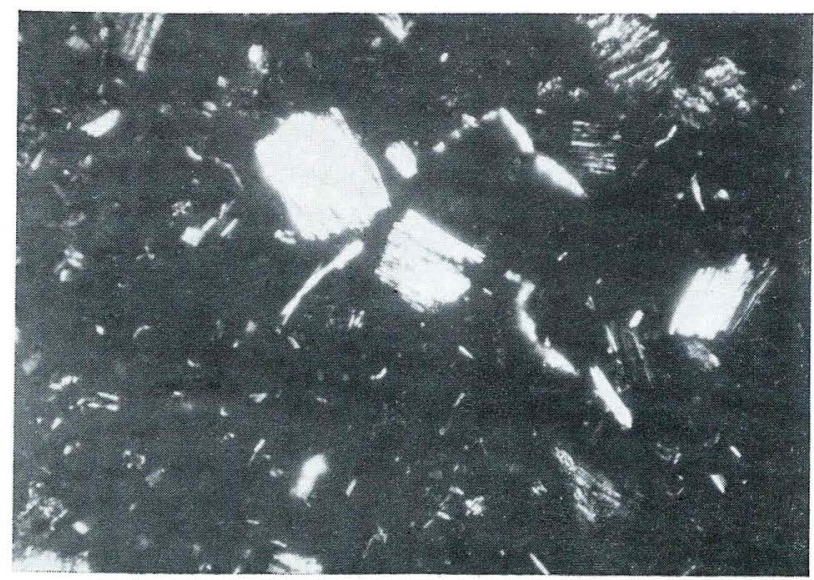

B: Cigar sheet 6

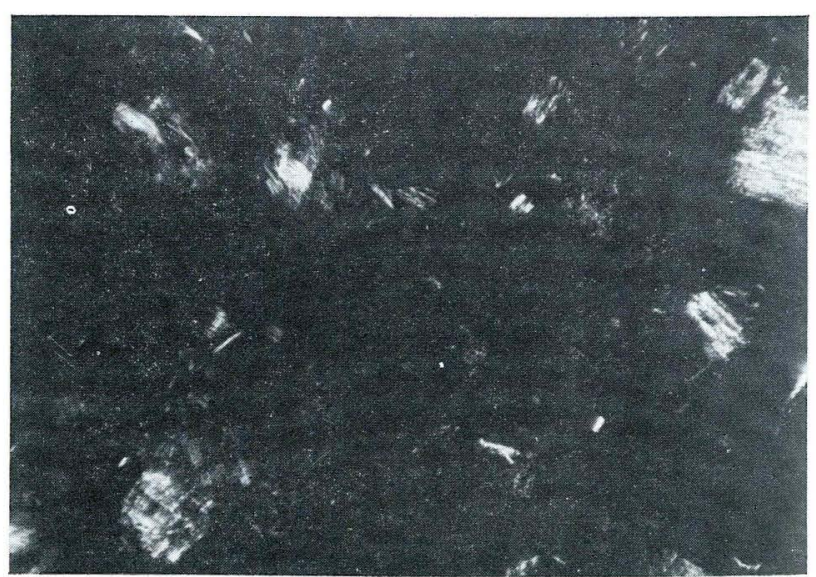


C: Cellulose isolated from Pennsylvania stem dust

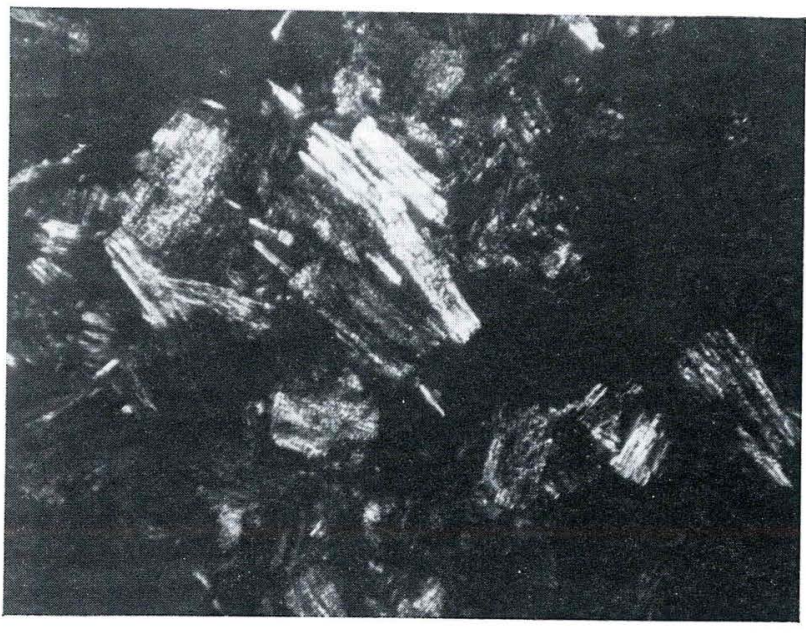

D: Cellulose isolated from Pennsylvania leaf dust

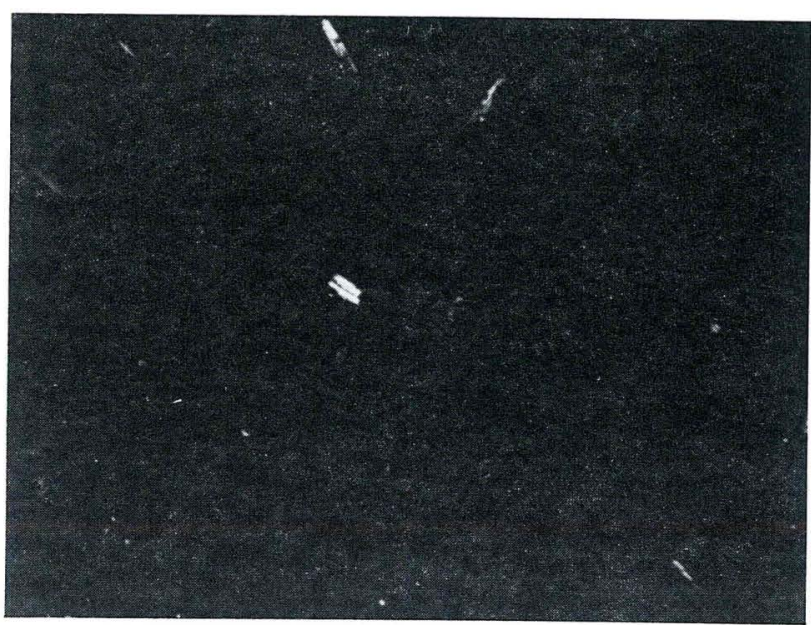

